\title{
Multilingual Assessment Instrument for Narratives (MAIN) adapted for use in West Frisian
}

\author{
Evelyn Bosma \\ Leiden University, Utrecht University
}

\section{Jelske Dijkstra}

Fryske Akademy, Mercator European Research Centre on Multilingualism and Language Learning

This paper describes the current state of affairs concerning the West Frisian adaptation of the Multilingual Assessment Instrument for Narratives (MAIN). We provide a short description of the West Frisian language, the process of adapting MAIN into West Frisian and the results of recent research using this adaptation.

\section{Introduction}

As most children have experience with storytelling and are used to storytelling across different contexts, both at home and in the classroom, narrative-based assessment provides an ecologically valid (Botting, 2002; Justice, Bowles, Pence, \& Gosse, 2010) and culturally sensitive (Price, Roberts, \& Jackson, 2006) way to examine children's language skills. Since narratives require the integration of language skills at various levels, including vocabulary, grammar, pragmatics and story processing (Bowles, Justice, Khan, Piasta, Skibbe, \& Foster, 2020), they can be analyzed in terms of both micro- and macrostructure. While microstructure refers to language use at word and sentence level, which is reflected in measures such as lexical diversity and mean length of utterance, macrostructure goes beyond this level and entails the global organization of the whole story, which is reflected in elements such as setting, character, and plot (Justice et al., 2010). As narratives, and especially macrostructure features, tap into language-general skills that can be compared across languages, narrative macrostructure is especially suited for bilingual language assessment (Gagarina, Klop, Tsimpli, \& Walters, 2016).

In this paper, we describe the creation of the West Frisian adaptation (revised in 2020) of a new narrative instrument that has been developed for language assessment in multilingual settings, the Multilingual Assessment Instrument for Narratives (MAIN; Gagarina et al., 2012, 
2015). MAIN is part of the Language Impairment Testing in Multilingual Settings (LITMUS) test battery (Armon-Lotem, de Jong, \& Meir, 2015) and has been revised in 2019 (Gagarina et al., 2019). This assessment instrument consists of four parallel stories (Cat, Dog, Baby Birds, Baby Goats) with three episodes that are displayed on a set of six pictures. Each story has its own protagonists and events, but the episodic structure is similar across the four stories. MAIN allows for three different ways of assessment: telling a story without the use of a model story (Telling), retelling the exact same story that the child has just listened to (Retelling), and telling a new story after the child has listened to a different, but structurally similar model story (Model story). For bilingual assessment, different stories should be used for the different languages that a child speaks, e.g. Cat and Baby Birds for language A and Dog and Baby Goats for language B. To examine children's narrative comprehension, each story has ten comprehension questions about goals and internal states. To examine children's narrative production, overall story structure, structural complexity and the total number of internal states are taken into account.

Like all of the MAIN versions, the West Frisian adaptation of MAIN consists of four parallel stories with the same ways of assessment and the same standardized procedures for scoring. In what follows, we first provide a short description of the West Frisian language, followed by a description of the process of adapting MAIN into West Frisian. Finally, we give a summary of the research that has so far been carried out with this adaptation.

\section{West Frisian}

West Frisian is a West Germanic language that is spoken as a regional minority language in the Dutch province of Fryslân, where it is recognized as an official language next to the national majority language Dutch. It is, however, much stronger in rural than in urban areas and it is predominantly used in informal domains (Breuker, 2001). All speakers of West Frisian also speak Dutch and Dutch is clearly the dominant language in education and the media (De Haan, 1997).

Three mutually intelligible main dialects are distinguished: 'Forest Frisian' (Wâldfrysk) in the east of the province, 'Clay Frisian' (Klaaifrysk) in the west, and 'Southwest Quarter' (Súdwesthoeks) in the southwest (De Jong \& Hoekstra, 2020; Hof, 1933; Tiersma, 1999). The first two are the main dialects on which the grammatical and lexical properties of written Standard West Frisian are based. As we will explain below, however, this written standard is hardly used within the Frisian speech community.

Although the West Frisian dialects are historically more closely related to English than to Dutch, extensive language contact with Dutch has resulted in convergence towards Dutch, both at the lexical and the structural level (Gooskens \& Heeringa, 2004). This has led to the situation that Standard West Frisian is different from the West Frisian language that its speakers use on a daily basis (De Haan, 1997). In fact, there is no general knowledge of the written standard: as the most recent sociolinguistic survey shows, most of the inhabitants of Fryslân are able to speak West Frisian well (69\%), but only few can write it well (18\%) (Klinkenberg, Jonkman, \& Stefan, 2018). This lack of knowledge of the standard creates a high tolerance of 
(dialect) variation and Dutch interference, which occurs at all linguistic levels: at the lexical level, the morphological level, the syntactical level and even the phonological level (Breuker, 2001; De Haan, 1997).

Linguistically, there are many parallels, but also differences, between West Frisian and Dutch. For example, like Dutch, West Frisian is a fusional language with Verb-Second (SVO) word order in main clauses and SOV word order in subordinate clauses. As in Dutch, attributive adjectives are placed before the noun. A contrast between Dutch and West Frisian is that West Frisian has pro-drop, which is only attested in the second person singular, e.g. -sto as a clitic in the subordinate clause omdatsto de fyts hast 'because you have the bike'. Furthermore, while Dutch only has one inflectional paradigm for regular verbs, West Frisian has two: Dutch regular verbs only have infinitives ending in -en (e.g. bakken 'to bake' and wonen 'to live'), while West Frisian regular verbs either have an infinitive ending in -e (bakke 'to bake') or in -je (wenje 'to live'). Both West-Frisian regular verb paradigms have their own inflections (for more information, see www.taalportaal.org).

\section{Creating a West Frisian MAIN version}

While there are several norm-referenced narrative instruments for Dutch, which are part of standardized language test batteries (e.g. Schlichting Test voor Taalproductie-II: Verhaaltest; "Schlichting Test for Language Production-II: Story Test"; Schlichting \& Spelberg, 2010; Renfrew Taalschalen Nederlandse Aanpassing; "Renfrew Language Scales Dutch Adaptation"; Van den Heuvel, Borgers, Ketelaars, \& Jansonius, 2016; Taaltoets Alle Kinderen; "Language Assessment All Children"; Verhoeven \& Vermeer, 2001), no such instruments exist for Frisian. MAIN could fill this gap. As MAIN is also available in Dutch (Blom, Boerman, \& De Jong, 2020) and comprises different stories with the same basic structure, it is suitable for FrisianDutch bilingual assessment and other combinations of languages.

MAIN was translated and adapted to West Frisian by two linguists, a near-native speaker (first author) and a native speaker (second author) of West Frisian, who both grew up in the West Frisian speech community. The first author created the first version of the West Frisian MAIN in 2013, which was a translation based on the English (Gagarina et al., 2012) and Dutch (Blom \& De Jong, 2013) versions of MAIN. Both authors adapted the West Frisian version in 2020, based on the revisions of the English (Gagarina et al., 2019) and Dutch (Blom, Boerma, \& De Jong, 2020) versions, following the guidelines for adapting MAIN to other languages (Bohnacker \& Gagarina, 2019).

The biggest challenge in the creation of the West Frisian version of MAIN was to bridge the gap between the West Frisian language as used in the speech community and the Standard West Frisian language as described in dictionaries and grammars. A translation of MAIN that completely follows the standard would sound unnatural and unacceptable, if not incomprehensible, to most West Frisian-speaking children. The West Frisian language used by the speech community contains Dutch interferences and loanwords due to close language contact, whereas the standard is more conservative and often prescriptive by nature. Therefore, 
we decided to adapt MAIN in such a way that it only contains (Standard) West Frisian vocabulary and grammar that is used in the speech community. For this reason, we predominantly used the Frysk Hânwurdboek ('Frisian Concise Dictionary', available at taalweb.frl) throughout the adaptation process and only included words that could be found in this dictionary. The Frysk Hânwurdboek comprises approximately 70,000 lemmas and, in contrast to other West Frisian dictionaries, also contains words from the last two decades. Consequently, both Standard West Frisian lemmas and lemmas of loanwords from Dutch that have already been adopted within colloquial West Frisian are included (Duijff \& Van der Kuip, 2008).

\section{Summary of research with the West Frisian MAIN}

To this date, the West Frisian version of MAIN has only been used in one published study. To classify 5- and 6-year-old Frisian-Dutch bilingual children $(N=122)$ as balanced or unbalanced bilinguals, Bosma, Blom and Versloot (2017) used Frisian and Dutch MAIN comprehension and production scores, together with Frisian and Dutch expressive morphology (Blom \& Bosma, 2016; Verhoeven \& Vermeer, 2001) and receptive vocabulary measures (Bosma, Blom, Hoekstra, \& Versloot, 2019; Schlichting, 2005). The production parts of the Dutch and Frisian MAIN were used to select children who could tell a story in Dutch, but not in Frisian. Subsequently, 30 children were selected from this group who performed better on Dutch morphology than on Frisian morphology. These 30 Dutch-dominant bilingual children were matched to 30 balanced bilingual children who produced a narrative in both languages and who performed similarly on Frisian and Dutch morphology. Statistical analyses showed that the two groups significantly differed from one another on all Frisian language measures, that is, narrative production, narrative comprehension, expressive morphology and receptive vocabulary, but that they performed similarly on all Dutch language measures.

Correlational analyses (not reported in Bosma et al., 2017) showed that Frisian narrative comprehension and production scores correlated significantly with other Frisian language measures. Frisian narrative comprehension correlated significantly with exposure to Frisian at home $(r(119)=.45, p<.001)$, Frisian narrative production $(r(120)=.47, p<.001)$, Frisian receptive vocabulary $(r(120)=.57, p<.001)$ and Frisian expressive morphology $(r(120)=.48$, $p<.001)$. Frisian narrative production also correlated significantly with intensity of exposure to Frisian at home $(r(119)=.72, p<.001)$, Frisian receptive vocabulary $(r(120)=.42, p<.001)$ and Frisian expressive morphology $(r(120)=.66, p<.001)$. (Note that children who were unable to produce a Frisian narrative obtained a score of 0 for Frisian narrative production.)

\section{$5 \quad$ Concluding remarks}

In combination with the Dutch MAIN, the Frisian MAIN is a promising measure for narrative assessment in Frisian-Dutch bilingual children. Previous research (Bosma et al., 2017) has 
shown that narrative comprehension and production scores show sufficient variation to assess (bilingual) language proficiency and that they significantly correlate with exposure and other language measures. The Frisian MAIN is thus a suitable measure to examine children's Frisian language skills.

\section{$6 \quad$ References}

Armon-Lotem, S., de Jong, J., \& Meir, N. (Eds.) (2015). Assessing multilingual children: Disentangling bilingualism from language impairment. Bristol: Multilingual Matters.

Blom, E., Boerma, T., \& De Jong, J. (2020). Multilingual Assessment Instrument for Narratives (MAIN) adapted for use in Dutch. ZAS Papers in Linguistics, 64, 51-56.

Blom, E., \& Bosma, E. (2016). The sooner the better? An investigation into the role of age of onset and its relation with transfer and exposure in bilingual Frisian-Dutch children. Journal of Child Language,43(3), 581607 .

Bohnacker, U., \& Gagarina, N. (2019). Background on MAIN - Revised, how to use it and adapt it to other languages. ZAS Papers in Linguistics, 63.

Bosma, E., Blom, E., \& Versloot, A. (2017). Language balance and cognitive advantages in Frisian-Dutch bilingual children. In F. Lauchlan \& M.C. Parafita Couta (Eds.), Bilingualism and Minority Languages in Europe: Current trends and developments (pp. 141-158). Cambridge: Cambridge Scholars Publishing.

Bosma, E., Blom, E., Hoekstra, E., \& Versloot, A. (2019). A longitudinal study on the gradual cognate facilitation effect in bilingual children's Frisian receptive vocabulary. International Journal of Bilingual Education and Bilingualism, 22(4), 371-385.

Botting, N. (2002). Narrative as a tool for the assessment of linguistic and pragmatic impairments. Child Language Teaching and Therapy, 18(1), 1-21.

Bowles, R. P., Justice, L. M., Khan, K. S., Piasta, S. B., Skibbe, L. E., \& Foster, T. D. (2020). Development of the Narrative Assessment Protocol-2: A Tool for Examining Young Children's Narrative Skill. Language, Speech, and Hearing Services in Schools, 51(2), 390-404.

Breuker, P. (2001). West Frisian in language contact. In H. H. Munske, N. Århammar, V. F. Faltings, J. F. Hoekstra, O. Vries, A. G. H. Walker, \& O. Wilts (Eds.), Handbook of Frisian studies (pp. 121-129). Tübingen: Max Niemeyer.

De Haan, G. J. (1997). Contact-induced changes in modern West Frisian. Us Wurk, 46(1-4), 61-89.

De Jong, G., \& Hoekstra, E. (2020). A general introduction to Frisian. Taalportaal. Retrieved from https://taalportaal.org/taalportaal/topic/pid/topic-14225224491227143 (accessed 14 May 2020).

Duijff, P. \& Van der Kuip, F. (Eds.) (2008). Frysk Hânwurdboek. Leeuwarden: Fryske Akademy.

Gagarina, N., Klop, D., Kunnari, S., Tantele, K., Välimaa, T., Balčiūnienè, I., Bohacker, U., \& Walters, J. (2012). MAIN: Multilingual Assessment Instrument for Narratives. ZAS Papers in Linguistics, 56.

Gagarina, N., Klop, D., Kunnari, S., Tantele, K., Välimaa, T., Balčiūnienė, I., Bohnacker, U., \& Walters, J. (2015). Assessment of Narrative Abilities in Bilingual Children. In S. Armon-Lotem, J. de Jong, \& N. Meir (Eds.), Assessing multilingual children disentangling bilingualism from language impairment (pp. 243-269). Bristol: Multilingual Matters. 
Gagarina, N., Klop, D., Kunnari, S., Tantele, K., Välimaa, T., Bohnacker, U., \& Walters, J. (2019). MAIN: Multilingual Assessment Instrument for Narratives - Revised. ZAS Papers in Linguistics, 63.

Gagarina, N., Klop, D., Tsimpli, I. M., \& Walters, J. (2016). Narrative abilities in bilingual children. Applied Psycholinguistics, 37(1), 11-17.

Gooskens, C., \& Heeringa, W. (2004). The position of Frisian in the Germanic language area. In D. Gilbers, M. Schreuder, \& N. Knevel (Eds.), On the Boundaries of Phonology and Phonetics (pp. 61-87). Groningen: University of Groningen.

Hof, J. J. (1933). Friesche dialectgeographie. 's Gravenhage: Nijhoff.

Justice, L. M., Bowles, R., Pence, K., \& Gosse, C. (2010). A scalable tool for assessing children's language abilities within a narrative context: The NAP (Narrative Assessment Protocol). Early Childhood Research Quarterly, 25(2), 218-234.

Klinkenberg, E., Jonkman, R., \& Stefan, N. (2018). Taal yn Fryslân: de folgjende generaasje. Leeuwarden: Fryske Akademy.

Price, J. R., Roberts, J. E., \& Jackson, S. C. (2006). Structural development of the fictional narratives of African American preschoolers. Language, Speech, and Hearing Services in Schools, 37(3), 178-190.

Schlichting, L. (2005). Peabody Picture Vocabulary Test-III-NL. Amsterdam: Harcourt Test.

Schlichting, J. E. P. T., \& Spelberg, H. C. L. (2010). Schlichting Test voor Taalproductie-II. Houten: Bohn Stafleu van Loghum.

Tiersma, P. M. (1999). Frisian Reference Grammar. Leeuwarden: Fryske Akademy.

Van den Heuvel, E., Borgers, M., Ketelaars, M., \& Jansonius, K. (2016). Renfrew Taalschalen Nederlandse Aanpassing. Antwerpen/Apeldoorn: Garant.

Verhoeven, L., \& Vermeer, A (2001). Taaltoets Alle Kinderen. Arnhem: Citogroep. 